\title{
Toward the Rapid Diagnosis of Sepsis: Detecting Interleukin-6 in Blood Plasma Using Functionalized Screen-Printed Electrodes with a Thermal Detection Methodology
}

Robert D. Crapnell, Whitchuta Jesadabundit, Alejandro García-Miranda Ferrari, Nina C. Dempsey-Hibbert,* Marloes Peeters, Ascanio Tridente, Orawon Chailapakul, and Craig E. Banks*

Cite This: Anal. Chem. 2021, 93, 5931-5938

Read Online

ABSTRACT: This paper reports the detection of the inflammatory and sepsisrelated biomarker, interleukin-6 (IL-6), in human blood plasma using functionalized screen-printed electrodes (SPEs) in conjunction with a thermal detection methodology, termed heat-transfer method (HTM). SPEs are functionalized with antibodies specific for IL-6 through electrodeposition of a diazonium linking group and $N^{\prime}$-ethylcarbodiimide hydrochloride (EDC) coupling, which was tracked through the use of cyclic voltammetry and Raman spectroscopy. The functionalized SPEs are mounted inside an additively manufactured flow cell and connected to the HTM device. We demonstrate the ability to detect IL-6 at clinically relevant concentrations in PBS buffer $(\mathrm{pH}=$ 7.4) with no significant interference from the similarly sized sepsis-related biomarker procalcitonin (PCT). The limit of detection $(3 \sigma)$ of the system is calculated to correspond to $3.4 \pm 0.2 \mathrm{pg} \mathrm{mL}^{-1}$ with a working range spanning the

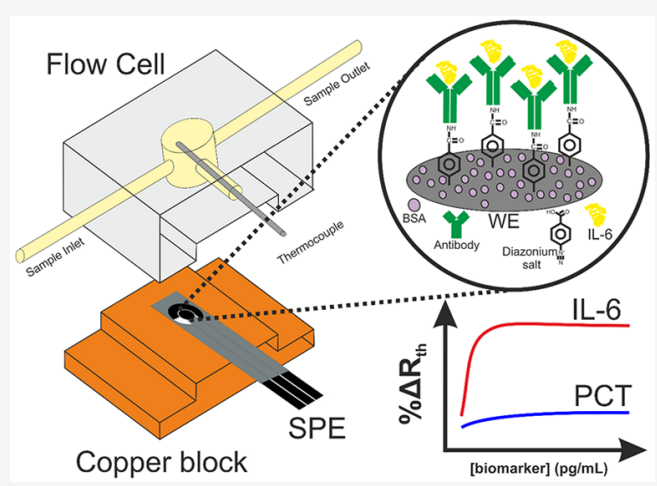
physiologically relevant concentration levels in both healthy individuals and patients with sepsis, indicating the sensitivity of the sensor is suitable for the application. Further experiments helped provide a proof-of-application through the detection of IL-6 in blood plasma with no significant interference observed from PCT or the constituents of the medium. Due to the selectivity, sensitivity, straightforward operation, and low cost of production, this sensor platform has the potential for use as a traffic light sensor for the multidetection of inflammatory biomarkers for the diagnosis of sepsis and other conditions in which the rapid testing of blood biomarkers has vital clinical application.

\section{INTRODUCTION}

The United Nations World Health Assembly has recognized sepsis as a global health priority with more than 19 million sepsis cases and 6 million annual sepsis-related deaths estimated to occur worldwide. ${ }^{1}$ It has been reported that, for every hour that sepsis remains undiagnosed in a patient and treatment is not initiated, there is a $7.6 \%$ reduction in patient survival rate, ${ }^{2}$ and hence, it is considered a medical emergency. Sepsis is defined as life-threatening organ dysfunction due to a dysregulated host response to infection. ${ }^{3}$ The infectious agent is the instigator, while the host's overexaggerated (hyperinflammatory) immune system is responsible for the widespread organ damage that is characteristic of the condition. Hence, current absolute diagnosis requires the evidence of a bloodstream infection (BSI) as well as indicators of systemic inflammation. A heightened understanding of the inflammatory processes that lead to host tissue damage in sepsis has led to the identification of several key biomarkers that allow for improved risk stratification and treatment decision making; These include biomarkers involved in the hyper-inflammatory "cytokine storm" and acute phase response. Indeed, there is considerable evidence demonstrating interleukin-6 (IL-6) in particular as a useful diagnostic and prognostic marker. ${ }^{4}$ Interestingly, the importance of IL-6 in the progression of severe respiratory illness and multiorgan failure in COVID-19 patients has recently been highlighted. Critically ill COVID-19 patients, by definition, have sepsis; they present with infection in the presence of organ dysfunction. Higher concentrations of this cytokine in COVID-19 patients are associated with more profound host tissue damage, progression to mechanical ventilation, and ultimately death. ${ }^{5}$ Further, the blockade of IL-6 has been suggested as a potential treatment approach for

Received: January 28, 2021

Accepted: March 22, 2021

Published: April 1, 2021 
critically ill COVID-19 patients, ${ }^{6}$ although the results from randomized controlled clinical trials are awaited.

Current testing methods for sepsis involve lengthy laboratory procedures for the detection of a BSI and also inflammatory markers with in vitro blood culture testing often taking up to $72 \mathrm{~h}$. Diagnosis is therefore often made on the basis of clinical judgment in the absence of laboratory results. It is clear that more rapid testing methods need to be developed. Approaches to overcome these lengthy turnaround times include multi-ELISA arrays ${ }^{8}$ and optical ${ }^{9}$ and electrochemical detection ${ }^{10}$ of biomarkers. The vast majority of the systems reported in the literature utilize specific antibodies as their recognition element, where the interaction between the target protein and the antibodies can be determined using a wide array of detection methods. For electrochemical detection, one way of immobilizing these antibodies onto the surface of an electrode is through carbodiimide-mediated coupling, ${ }^{11}$ which involves the formation of an amide bond between either a carboxyl or amine group on the antibody and the counter group on the surface. The modification of the electrodes with moieties containing these functional groups can be achieved simply through the electrografting of diazonium salts. This involves the irreversible one electron reduction of the diazonium salt and the formation of a covalent bond between it and the surface of the electrode. This has been shown for various electrode materials such as gold ${ }^{12}$ and carbon. ${ }^{13}$ Using screen-printed electrodes (SPEs) is advantageous over other electrode materials due to their high reproducibility, low cost, and suitability for mass production. ${ }^{14}$ The electrografting of diazonium salts onto SPEs and coupling antibodies for the purpose of electrochemical biosensor production are well explored research areas. ${ }^{15}$ However, there have been no reports in the literature of this methodology used in conjunction with thermal detection. The heat-transfer method (HTM) is a thermal detection method that utilizes the heat-transfer resistance at the solidliquid interface. Its first use for medical diagnostics was described in $2012^{16}$ for the monitoring of mutations in DNA. This method has the advantage of low cost and label free analysis, which synergizes well with the use of SPEs. The HTM has since been used for the detection of small molecules ${ }^{17}$ and proteins ${ }^{18}$ as well as monitoring bacteria ${ }^{19}$ with an emphasis on its use in conjunction with molecularly imprinted polymers (MIPs) due to the large amounts of cavities provided. There have been no attempts to utilize antibodies for a biosensing platform alongside the HTM reported in the literature, most likely due to the smaller surface coverage. Improvements to the measurement design have allowed for improved specificity, leading to the ability to detect antigen-antibody interactions. This work presented herein reports the possibility to open up completely new fields of research for the HTM and thermal detection due to the vast array of uses for antibodies and the adaptability of the proposed sensing platform.

Consequently, in this paper, we present the first report of antibody-based biorecognition in conjunction with the HTM for the label-free detection of the inflammatory marker IL-6 in blood plasma. The SPEs are functionalized through electrografting a suitable carboxyphenyl film onto the surface via the reduction of a diazonium salt, followed by the antibody immobilization through the $N^{\prime}$-ethylcarbodiimide hydrochloride (EDC) $/ N$-hydroxysuccinimide (NHS) coupling process. These functionalized electrodes are then used for the detection of IL-6 in conjunction with the HTM in both buffered solutions and, more importantly, human plasma. The successful measurement of IL-6 in clinically relevant ranges, using a small sample size $(\sim 100 \mu \mathrm{L})$ and in under $45 \mathrm{~min}$ (which could be reduced further through optimization of the baseline measurements and an injection procedure ${ }^{20}$ ), indicate its promise for a point-of-care testing system that could lead to dramatic decreases in sepsis-related mortality. This study shows the potential for the widespread use of this technology, in research and practice, due to its low cost of production and through the ability to monitor antigen-antibody interactions in real-time.

\section{EXPERIMENTAL SECTION}

Materials and Instruments. All chemicals were purchased and used without further purification. Sodium nitrite, 4aminobenzoic acid, $N$-(3-(dimethylamino)propyl)- $N^{\prime}$-ethylcarbodiimide hydrochloride (EDC), $N$-hydroxysuccinimide (NHS), bovine serum albumin (BSA), Tween 20, and potassium ferrocyanide were obtained from Merck Life Science UK Limited (Gillingham, United Kingdom). Hydrochloric acid was purchased from Fisher Scientific (Loughborough, United Kingdom). Recombinant human interleukin-6 (IL-6) protein (200-06) and anti-human IL-6 antibodies (500-M06) were purchased from PeproTech EC Ltd. (London, United Kingdom). Procalcitonin (PCT) was purchased from Abcam PLC (Cambridge, United Kingdom). Phosphate buffered saline (PBS) solutions were prepared using PBS tablets purchased from Merck Life Science UK Limited (Gillingham, United Kingdom) and deionized water of resistivity not less than $18.2 \mathrm{M} \Omega \mathrm{cm}$. Human blood plasma was purchased from the NHS Blood \& Transplant Service (NHSBT), therefore alleviating the need for HRA approval. The plasma was obtained as fresh frozen plasma (FFP) and was defrosted at room temperature prior to use in the experiments. All FFP used was Group $\mathrm{O} \mathrm{RhD}$ positive. Raman spectroscopy was performed on a Renishaw PLC in Via Raman microscope controlled by WiRE 2 software at a laser wavelength of 514 $\mathrm{nm}$.

Electrochemical Measurements. All electrochemical experiments were performed in solutions purged with highly pure nitrogen at $20 \pm 1{ }^{\circ} \mathrm{C}$ on a Metrohm AG Autolab PGSTAT101 (Utrecht, The Netherlands) controlled by NOVA 2.0. All measurements were conducted using screenprinted electrodes (SPEs; Manchester Metropolitan University). ${ }^{21}$ Briefly, the SPEs were fabricated in-house using a stencil design to achieve a $3.1 \mathrm{~mm}$ diameter working electrode using graphite ink (Product Ink: C2000802P2; Gwent Electronic Materials Ltd., Pontypool, United Kingdom) and were printed using a DEK 248 screen printer machine (DEK, Weymouth, United Kingdom) onto a polyester flexible film (250 $\mu \mathrm{m}$ thickness; Autostat, Milan, Italy). The layer was cured in a fan oven at $60{ }^{\circ} \mathrm{C}$ for $30 \mathrm{~min}$. Next, a silver/silver chloride reference electrode was introduced by screen-printing $\mathrm{Ag} \mid \mathrm{AgCl}$ paste (Product Code: D2070423D5; Gwent Electronic Materials Ltd., Pontypool, United Kingdom) onto the polyester substrates and cured in a fan oven for $30 \mathrm{~min}$ at 60 ${ }^{\circ}$ C. Finally, a dielectric paste (Product Code: D2070423D5; Gwent Electronic Materials Ltd., Pontypool, United Kingdom) was then printed onto the polyester substrate to cover the connections and cured for an additional $30 \mathrm{~min}$ at $60{ }^{\circ} \mathrm{C}$ before use. $^{22}$

Tracking and identification of the electrode modification was performed using cyclic voltammetry in conjunction with 


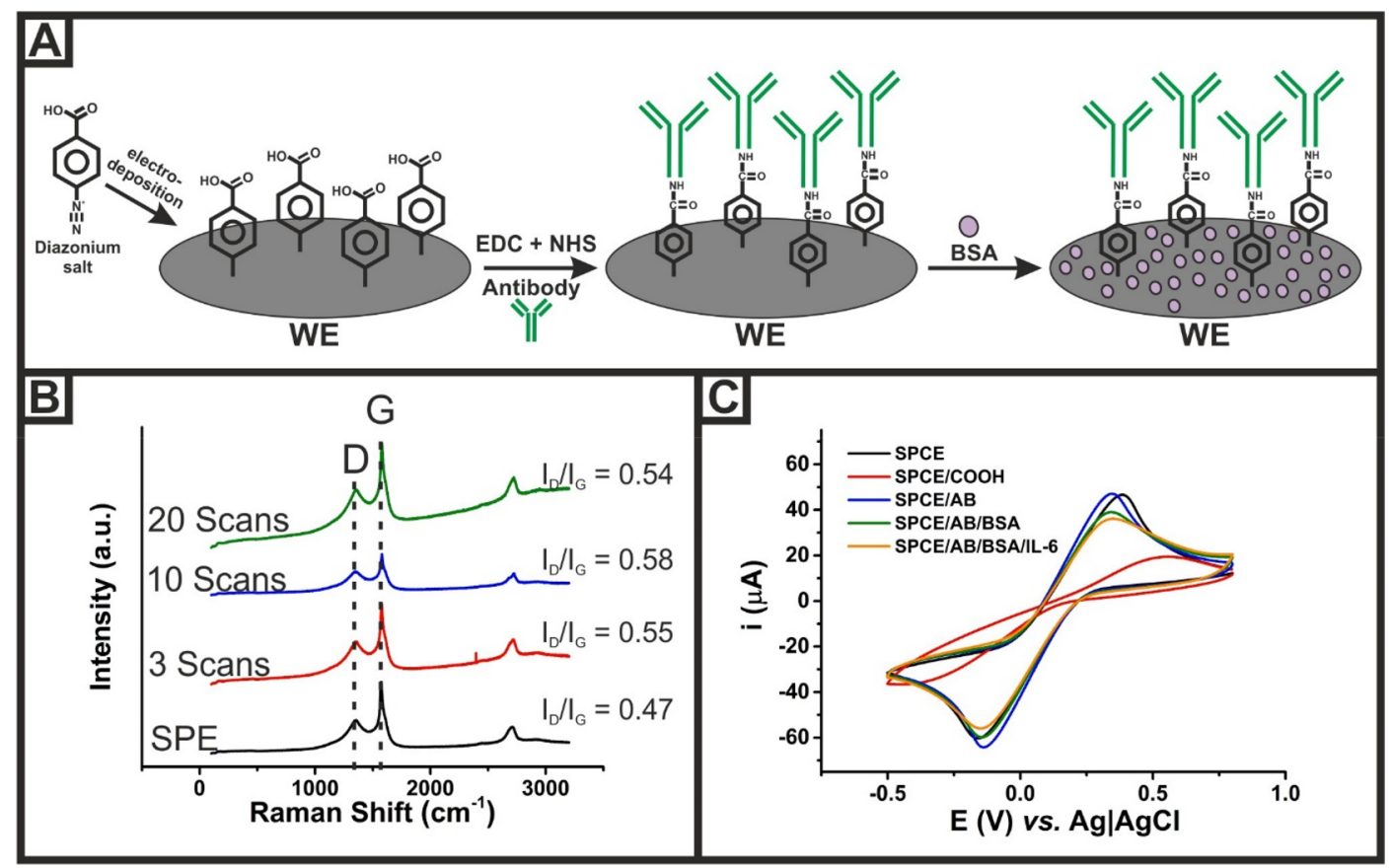

Figure 1. (A) Schematic depicting the functionalization of a screen-printed electrode (SPE) with antibodies specific for interleukin-6. (B) Raman spectroscopy for the functionalization of screen-printed carbon electrodes with diazonium linking groups using different amounts of scans in cyclic voltammetry. (C) Cyclic voltammograms for $\left[\mathrm{Fe}(\mathrm{CN})_{6}\right]^{3-/ 4-}(10 \mathrm{mM})$ in $0.1 \mathrm{M} \mathrm{KCl}$ after each step of the electrode functionalization procedure, including the incubation with interleukin-6.

$\left[\mathrm{Fe}(\mathrm{CN})_{6}\right]^{3-/ 4-}$ as the redox probe. A solution of $[\mathrm{Fe}-$ $\left.(\mathrm{CN})_{6}\right]^{3-/ 4-}(10 \mathrm{mM})$ was prepared in $\mathrm{KCl}(0.1 \mathrm{M})$ and degassed with pure nitrogen for $15 \mathrm{~min}$. A droplet of $40 \mu \mathrm{L}$ was deposited onto the SPE, making sure all three electrodes were fully covered, and cyclic voltammetry was performed at a scan rate of $50 \mathrm{mV} \mathrm{s}^{-1}$ between -0.5 and $+0.8 \mathrm{~V}$.

Heat-Transfer Measurements. Once functionalized (see below), SPEs were cut into $1 \times 1 \mathrm{~cm}$ squares, inserted into an additively manufactured (AM) flow cell, ${ }^{18 \mathrm{~b}}$ and sealed with an O-ring (RS Components, Stockport, United Kingdom); see Figure S1A. Thermal measurements were carried out using a flow cell (Figure 2A) with an internal volume of $110 \mu \mathrm{L}$ in conjunction with the heat-transfer setup. ${ }^{16}$ The flow cell was connected to a copper block that acts as a heat sink. The temperature of the block $\left(T_{1}\right)$ is controlled via a proportionalintegral-derivative (PID). The PID parameters can affect the power signal stability and therefore the sensitivity of the developed sensor. As such, these values were set to the optimized values determined for this heat source of $P=1, I=$ 14 , and $D=0.3 .^{18 \mathrm{~b}}$ A type-K thermocouple (RS Components, Stockport, United Kingdom) is used to measure the temperature of the sample solution $\left(T_{2}\right) 1.7 \mathrm{~mm}$ above the surface of the SPE. The thermal resistance $\left(R_{\mathrm{th}}\right)$ at the solid-liquid interface can be determined by dividing the measured temperature difference between the copper block and the solution $\left(T_{1}-T_{2}\right)$ by the power provided to the heat source to maintain its temperature; the HTM device is presented in Figure S1B.

For aqueous experiments, the flow cell was placed inside an incubator $\left(20 \pm 0.02{ }^{\circ} \mathrm{C}\right.$, INCU-Line, VWR, Leicestershire, United Kingdom) and was filled with PBS ( $\mathrm{pH}=7.4)$, and the copper block was heated to a predetermined temperature of 37 $\pm 0.02{ }^{\circ} \mathrm{C}$. The cell was left to stabilize for $45 \mathrm{~min}$ before the first injection in order to establish a baseline reading. Following this, sequential $2 \mathrm{~mL}$ additions of IL-6 protein (5-1000 pg
$\mathrm{mL}^{-1}$ ) in PBS were injected into the flow cell through silicone tubing (Fisher Scientific, Loughborough, United Kingdom) using an automated NE500 programmable syringe pump (Prosense, Oosterhout, The Netherlands) at a flow rate of 250

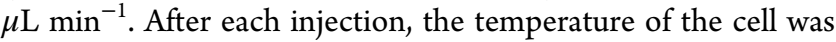
allowed to stabilize for $30 \mathrm{~min}$ to establish a reading. For each concentration, the last $10 \mathrm{~min}$ of each stabilization, which corresponds to 600 data points, was averaged out and used to calculate $R_{\mathrm{th}}$. These experiments were carried out in triplicate to prove the reproducibility of the results. The calculated $R_{\mathrm{th}}$ values were used to produce dose-response curves and mathematically calculate the limit of detection (LOD) using the three sigma method from the linear section of the logarithmic plot. Specificity tests were carried out by injecting $2 \mathrm{~mL}$ of the same concentration of the competitive target procalcitonin (PCT). To test the system in a relevant biological media, the flow cell was stabilized in blood plasma and then $2 \mathrm{~mL}$ of IL-6 (5-1000 pg mL $\left.{ }^{-1}\right)$ in blood plasma was injected into the cell. These experiments were repeated with PCT in blood plasma.

Sensor Fabrication. The stepwise electrode preparation is illustrated in Figure 1A. First, a diazonium layer was electrochemically deposited onto the surface of the SPEs. A solution of 4-aminobenzoic acid $(2 \mathrm{mM})$ and sodium nitrite (2 $\mathrm{mM})$ was prepared in $\mathrm{HCl}(0.5 \mathrm{M})$ and placed on a rocking table for $10 \mathrm{~min}$. A $50 \mu \mathrm{L}$ droplet of this solution was placed onto the surface of the SPEs, making sure all three electrodes were fully covered. The electrodeposition of the diazonium layer was achieved through applying 3 cyclic voltammetric sweeps from +0.2 to $-0.6 \mathrm{~V}$ at a scan rate of $100 \mathrm{mV} \mathrm{s}^{-1}$. Subsequently, the carboxyl functionalization was activated through incubation with a solution of EDC $(100 \mathrm{mM})$ and NHS $(20 \mathrm{mM})$ in PBS buffer $(\mathrm{pH}=5)$ on the working electrode for $1 \mathrm{~h}$. Next $7.5 \mu \mathrm{L}$ of the anti-IL-6 antibody $(10 \mu \mathrm{g}$ $\left.\mathrm{mL}^{-1}\right)$ in $\mathrm{PBS}(\mathrm{pH}=7.4)$ was dropped onto the working 


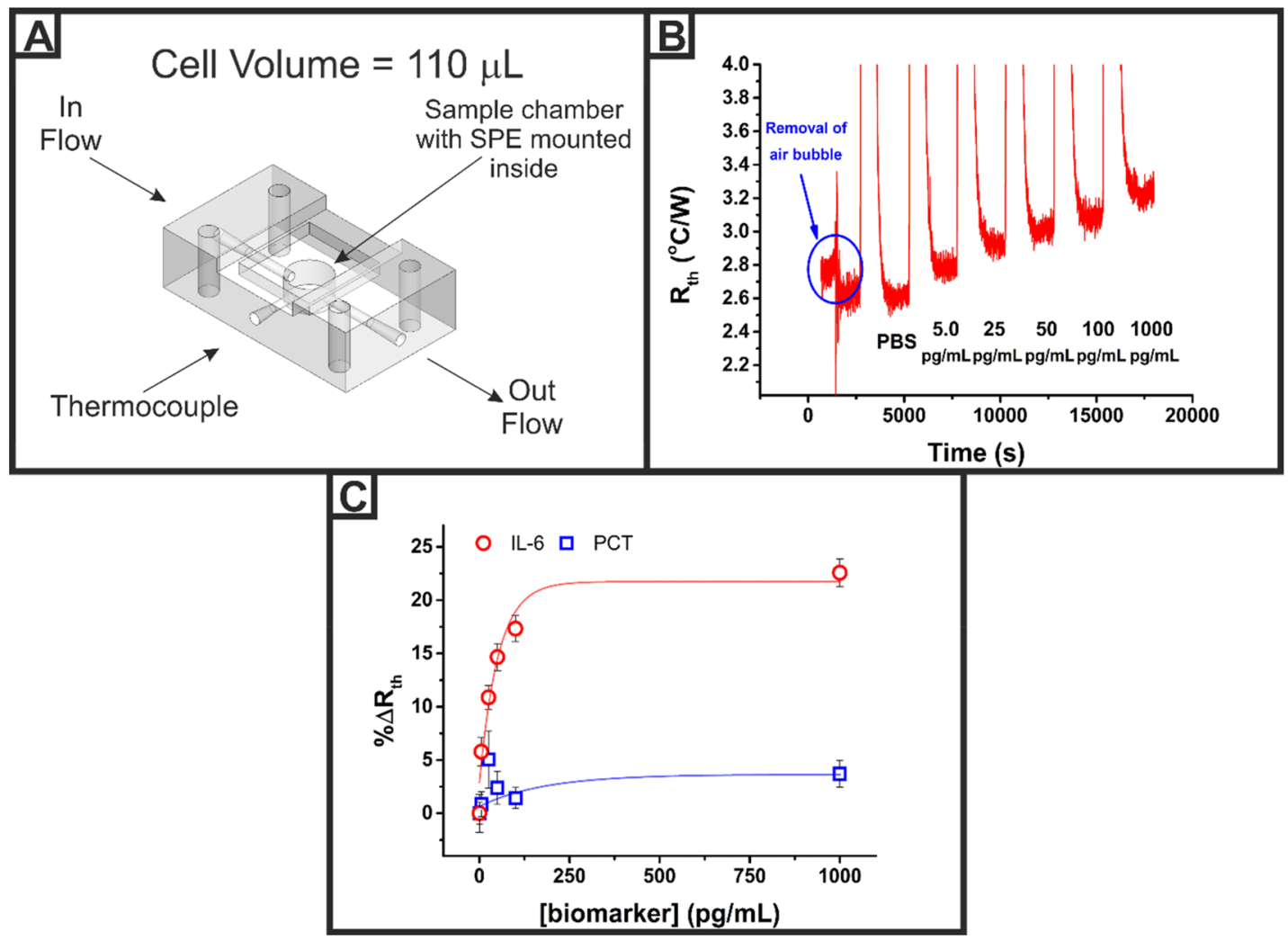

Figure 2. (A) Schematic representation of the flow cell used for HTM measurements, consisting of a sample chamber, sample inlet and outlet, and a thermocouple slot. (B) Raw HTM data plot for the addition of IL-6 $(5-1000 \mathrm{pg} / \mathrm{mL}$ ) in PBS to an electrode functionalized with IL-6 antibodies. (C) Dose response curves for the percentage change in the measured thermal resistance $\left(R_{\mathrm{th}}\right)$ for the addition of IL-6 (red) and PCT (blue) in PBS to an electrode functionalized with IL-6 antibodies. Note that, due to the HTM, occasionally, air bubbles can affect the measurements (see panel B) due to the physical constraints of the flow cell (see panel A).

electrode surface for $3 \mathrm{~h}$ at room temperature to immobilize the antibodies. Finally, the electrodes were incubated with a solution of BSA (1 wt \%) in PBS ( $\mathrm{pH}=7.4$ ) for $30 \mathrm{~min}$ to mitigate any nonspecific interactions with activated carboxyl groups and the free electrode surface. Following functionalization, the electrodes were stored in PBS $(\mathrm{pH}=7.4)$ at $4{ }^{\circ} \mathrm{C}$ until use.

\section{RESULTS AND DISCUSSION}

Antibody Functionalization of the Screen-Printed Electrodes (SPEs). The functionalization of the screenprinted electrodes (SPEs) was achieved through a multistep process, as summarized in Figure 1A. This involved the electrografting of a carboxyphenyl film onto the graphite surface of the working electrodes of the SPEs, followed by activation of the carboxyl group through EDC/NHS coupling, then immobilization of antibodies specific for IL-6, and finally, blocking of the free surface with BSA. The electrografting of the carboxyphenyl group onto the graphite surface of the SPEs was achieved through the electrochemical reduction of a diazonium salt using cyclic voltammetry cycled between +0.2 and $-0.6 \mathrm{~V}$ at $100 \mathrm{mV} \mathrm{s}^{-1}$. The cyclic voltammograms exhibited the characteristic irreversible peak between -0.2 and $-0.3 \mathrm{~V}$ for the one electron reduction of the carboxyphenyl diazonium salt, followed by the decrease in peak current intensity for the subsequent scans. This decrease is attributed to the increase of carboxyphenyl groups covalently attached to the surface of the electrode that leads to a decrease in the electron transfer efficiency between the diazonium salt and the electrode surface. ${ }^{23}$ This process was performed for different numbers of scans and analyzed through Raman spectroscopy, Figure $1 \mathrm{~B}$, to track the formation of the carboxyphenyl film on the surface of the working electrode. The bare SPEs exhibited the characteristic behavior with a $\mathrm{D}$ and $\mathrm{G}$ peak observed, associated with the $\mathrm{sp}^{3}$ defects and $\mathrm{sp}^{2}$ hybridized carbon vibrations, respectively. ${ }^{24}$ The enhancement of the $\mathrm{D}$ peak observed in the Raman spectrum after the electrografting procedure indicates the increase in $\mathrm{sp}^{3}$ carbons on the surface due to the formation of $\mathrm{C}-\mathrm{C} \mathrm{sp}^{3}$ bonds after carboxyphenyl covalent attachment. ${ }^{25}$ Following three cyclic voltammetric scans, the reduction peak of the diazonium salt was suitably reduced to indicate the partial blocking of the surface by the carboxyphenyl film. Following this, the antibody was immobilized onto the film through the activation of the carboxylic acid groups via EDC/NHS coupling. After this coupling process, the cyclic voltammetric peak for $[\mathrm{Fe}-$ $\left.(\mathrm{CN})_{6}\right]^{3-/ 4-}$ exhibited an increase in the current intensity attributed to the neutralization of a negatively charged carboxyl group on the surface. ${ }^{26}$ After confirmation of the covalent attachment of the antibody to the working electrode surface was obtained, the electrode was incubated in $10 \mathrm{pg} \mathrm{mL}^{-1} \mathrm{IL}-6$ target protein to observe any response using cyclic voltammetry. There was a small observed decrease in the $\left[\mathrm{Fe}(\mathrm{CN})_{6}\right]^{3-/ 4-}$ peak current intensity, indicating the binding of the protein to the antibody on the SPE surface, and a subsequent increase in the resistance to electron transport. Once proof of modification was obtained, the functionalized SPE was tested for its response to IL-6 across a wide range of 


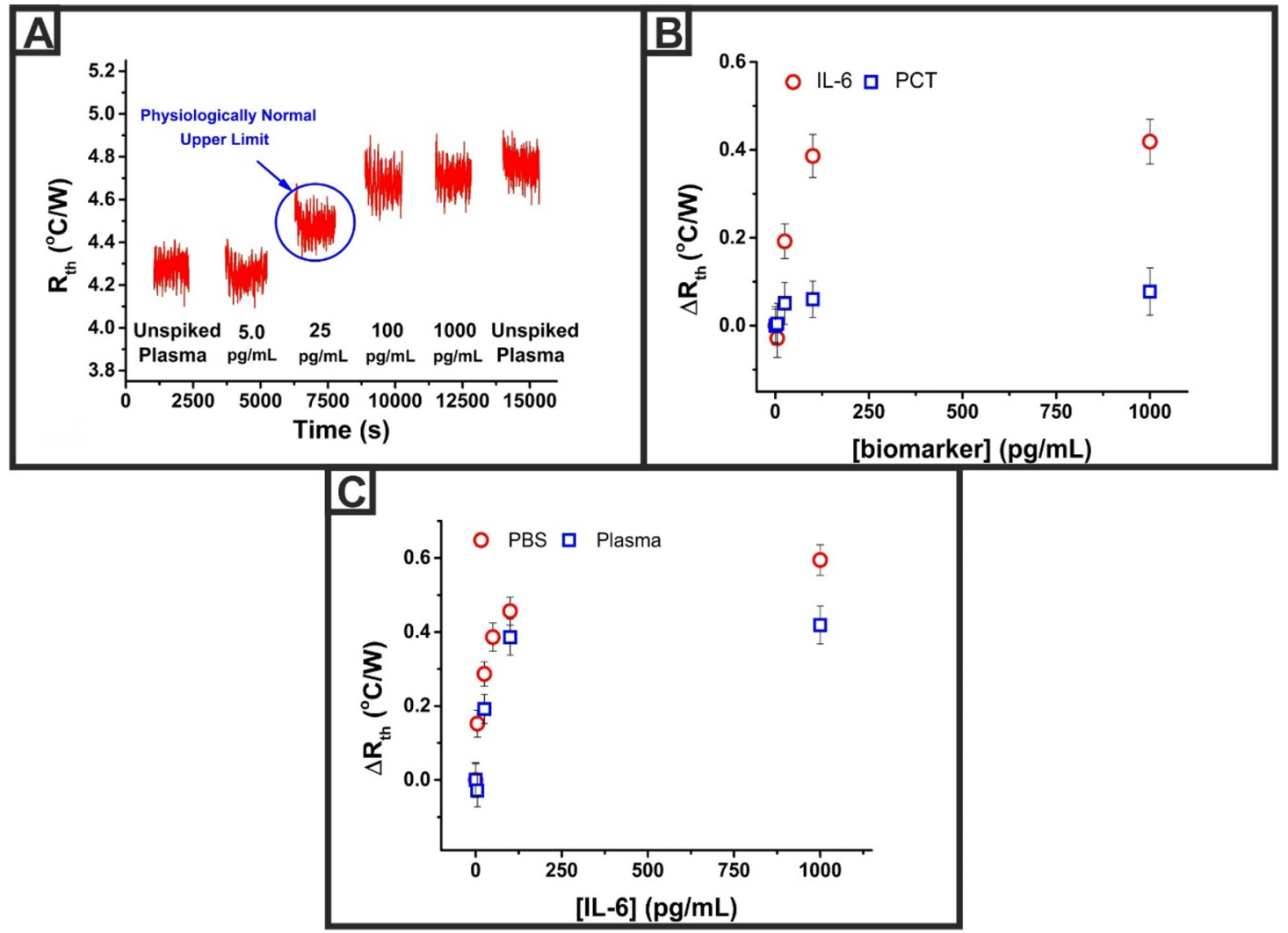

Figure 3. (A) Raw HTM data plot for the addition of IL-6 (5-1000 pg/mL) in blood plasma to an electrode functionalized with IL-6 antibodies. (B) Plot of the change in measured thermal resistance $\left(R_{\mathrm{th}}\right)$ for the addition of IL-6 (red) and PCT (blue) in blood plasma to an electrode functionalized with IL-6 antibodies. (C) Plot of the change in measured thermal resistance $\left(R_{\mathrm{th}}\right)$ for the addition of IL-6 in PBS (red) and blood plasma (blue) to an SPE functionalized with IL-6 antibodies.

relevant concentrations in conjunction using a thermal detection methodology via the use of the HTM.

Thermal Detection of IL-6. In order to check the viability of the modified SPEs and sensor platform for the detection of the sepsis biomarker IL-6, initial experiments were performed using solutions of IL-6 in PBS $(\mathrm{pH}=7.4)$. The antibody modified electrodes were cut down to a $1 \times 1 \mathrm{~cm}$ square around the working electrode and mounted inside an AM flow cell, Figure 2A, using an O-ring and copper block. The copper block was set to a temperature of $37.00 \pm 0.02{ }^{\circ} \mathrm{C}$, which was maintained throughout the measurements. First, the cell was filled with a blank solution of PBS an allowed to equilibrate for $45 \mathrm{~min}$ to establish a baseline reading and all readings were taken from an average of the final $10 \mathrm{~min}$ of each concentration (corresponding to 600 data points). As can be observed in the raw data plot in Figure 2B, there is a large spike in the baseline reading that corresponds to the removal of air bubble in the cell. Air bubbles can inflate the $R_{\mathrm{th}}$ values and cause a drift upward, which can be observed in the values just before air removal. Following this, a stable baseline is obtained from which to measure. Following the 45 min stabilization period, an extra injection of blank PBS was added to confirm the new baseline was accurate, and then, sequentially increasing concentrations of IL-6 (5-1000 pg mL $\left.\mathrm{mL}^{-1}\right)$ in PBS were introduced into the system using an automated pump at a rate of $250 \mu \mathrm{L} \mathrm{min}{ }^{-1}$; it was then allowed to stabilize for $30 \mathrm{~min}$. The large vertical spikes in the raw data plot seen in Figure 2B correspond to these injections. As the solution being injected is stored at room temperature in the syringe, there is a sharp initial spike in the resistance as the solution is heated.
Following each injection and stabilization, the last $10 \mathrm{~min}(600$ data points) of each concentration measurement is used to calculate an average $R_{\mathrm{th}}$ measurement. In PBS, the $R_{\mathrm{th}}$ value stabilized at a value of $2.63 \pm 0.05{ }^{\circ} \mathrm{C} / \mathrm{W}$ for the functionalized electrode. Upon the injection of the first concentration of IL-6, the measured $R_{\text {th }}$ value increased to a value of $2.79 \pm 0.04{ }^{\circ} \mathrm{C} /$ $\mathrm{W}$, which corresponded to a $6 \pm 2 \%$ rise in the signal. An increase in $R_{\mathrm{th}}$ was observed for all concentrations of IL-6 added to the flow cell, including for the highest concentration of $1000 \mathrm{pg} \mathrm{mL}^{-1}$ that stabilized at a value of $3.23 \pm 0.04{ }^{\circ} \mathrm{C} /$ $\mathrm{W}$, which was equivalent to a $23 \pm 1 \%$ increase. These results were used to calculate the intra-assay coefficient of variation $(\% \mathrm{CV})$ of $1.3 \%$. The work was repeated in triplicate to produce an interassay $\% \mathrm{CV}$ of $9 \%$, and the results were plotted in the form of a dose-response curve (Figure 2C), which was used to calculate the limit of detection (LOD) of $3.4 \pm 0.2 \mathrm{pg}$ $\mathrm{mL}^{-1}$, on the basis of the $3 \sigma$ method using the logarithmic linear plot of formula of $y=0.21 x+2.64\left(R^{2}=0.98\right)$. To show that the change in the measured $R_{\mathrm{th}}$ is due to the specific binding of IL- 6 to the antibodies immobilized on the surface of the electrode, experiments were conducted by injecting IL-6 (5-2000 $\mathrm{pg} \mathrm{mL}^{-1}$ ) to SPEs with no antibodies (only blocked with BSA) and to SPEs functionalized with procalcitonin antibodies (Figures S2 and S3, respectively). No significant change in the measured $R_{\mathrm{th}}$ was observed in either case, indicating that there was no binding of IL-6 onto the surface of the electrode. In addition to this, a similarly sized and relevant protein procalcitonin (PCT) was injected into the system, Figure $2 \mathrm{C}$. In this case, the baseline $R_{\mathrm{th}}$ stabilized at a value of $3.40 \pm 0.04{ }^{\circ} \mathrm{C} / \mathrm{W}$. For the injections of PCT, there is no 
Table 1. Compilation of Published Sensor Platforms for the Detection of Interleukin-6 (IL-6), Comparing Their Detection Methodologies, Limits of Detection and Viability in Biological Media

\begin{tabular}{|c|c|c|c|c|c|c|c|}
\hline $\begin{array}{l}\text { recognition } \\
\text { method }\end{array}$ & primary substrate & detection method & $\begin{array}{l}\text { incubation time } \\
(\text { min })\end{array}$ & $\begin{array}{l}\text { limit of detection } \\
\quad\left(\mathrm{pg} \mathrm{mL} \mathrm{mL}^{-1}\right)\end{array}$ & 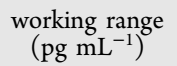 & $\begin{array}{l}\text { serum/plasma } \\
\text { tested? }\end{array}$ & reference \\
\hline antibodies & $\mathrm{ITO}^{a} / \mathrm{TiO}_{2} / \mathrm{CdS}$ & photoelectrochemical & 60 & 0.38 & $1-100000$ & no & 27 \\
\hline antibodies & $\mathrm{ITO}^{a} / \mathrm{AuNP}^{b}-\mathrm{PDOP}^{c}$ & amperometric & 110 & 1.0 & $4-800$ & yes & 28 \\
\hline antibodies & $\mathrm{Au}$ & $\mathrm{DPV}^{g}$ & 2.5 & $\mathrm{~N} / \mathrm{A}$ & $0-60$ & yes & $10 \mathrm{e}$ \\
\hline aptamer & $\mathrm{GCE}^{d}$ & EIS $^{h}$ & 60 & 1.6 & $5-100000$ & yes & 29 \\
\hline antibodies & $\mathrm{Al}_{2} \mathrm{O}_{3} /$ nanoAu & conductometric & 30 & 5 & $25-400$ & yes & 30 \\
\hline antibodies & ELISA $^{e}$ & ELISpot & 480 & 39 & $39-2500$ & yes & 31 \\
\hline antibodies & $\mathrm{Au}$ & $\operatorname{SPR}^{i}$ & 40 & 11.29 & $5-20$ & yes & 32 \\
\hline aptamer & $\mathrm{Au} / \mathrm{AuNP} \mathrm{P}^{b}$ & $\mathrm{EIS}^{h}$ & 60 & 0.02 & $0.02-200$ & no & 33 \\
\hline antibodies & $\mathrm{SPEs}^{f}$ & thermal & $<45$ & 3.37 & $5-1000$ & yes & $\begin{array}{l}\text { present } \\
\text { study }\end{array}$ \\
\hline
\end{tabular}

${ }^{a}$ Indium tin oxide. ${ }^{b}$ Gold nanoparticles. ${ }^{c}$ Polydopamine. ${ }^{d}$ Glassy carbon electrode. ${ }^{e}$ Enzyme-linked immunosorbent assay. ${ }^{f}$ Screen-printed electrodes. ${ }^{g}$ Differential pulse voltammetry. ${ }^{h}$ Electrochemical impedance spectroscopy. ${ }^{i}$ Surface plasmon resonance.

significant increase in the measured $R_{\mathrm{th}}$ until the addition of 25 pg mL ${ }^{-1}$, where $R_{\mathrm{th}}$ stabilized at a value of $3.57 \pm 0.1{ }^{\circ} \mathrm{C} / \mathrm{W}$, corresponding to an increase of $5 \pm 3 \%$. In comparison to the system where IL-6 was added, for $25 \mathrm{pg} \mathrm{mL}^{-1}, R_{\mathrm{th}}$ showed an increase of $11 \pm 1 \%$. Additionally, there is a larger amount of error observed in the PCT measurement for this concentration. After this addition, $R_{\mathrm{th}}$ falls again closer to the baseline and finally ends at an increase of $4 \pm 1 \%$. This shows that the sensing platform is specific for the detection of IL-6.

Thermal Detection of IL- 6 in Blood Plasma. To provide proof-of-application, experiments were performed using blood plasma as the medium spiked with IL- 6 and then PCT. In this way, blood plasma was injected into the system and allowed to stabilize for $45 \mathrm{~min}$ to form a baseline, Figure 3A. $R_{\mathrm{th}}$ stabilized at a value of $4.29 \pm 0.04{ }^{\circ} \mathrm{C} / \mathrm{W}$, which as expected due to the added elements in blood serum, was significantly higher than the baseline for PBS, even when including the errors in thermocouple absolute measurements. The complexity of the media also accounted for the increase in the noise of the signal and standard deviation. For the smallest injection of $5 \mathrm{pg} \mathrm{mL}^{-1}$ IL-6, there was no observed significant increase in the measured $R_{\mathrm{th}}$ value, which can be due to the presence of blood proteins (and other constituents) fouling the electrode surface and hampering detection. ${ }^{18 \mathrm{~b}}$ However, when $25 \mathrm{pg}$ $\mathrm{mL}^{-1}$ IL- 6 was introduced, $R_{\mathrm{th}}$ increased to a value of $4.48 \pm$ $0.04{ }^{\circ} \mathrm{C} / \mathrm{W}$. This increase continued for the addition of $100 \mathrm{pg}$ $\mathrm{mL}^{-1} \mathrm{IL}-6$, where $R_{\mathrm{th}}$ stabilized at a value of $4.67 \pm 0.04{ }^{\circ} \mathrm{C} /$ $\mathrm{W}$, indicating that it is possible to detect clinically relevant increases in the IL- 6 concentration above the normal physiological range in blood plasma. The gradients of the logarithmic linear plots for both PBS and blood plasma (0.21 and 0.20 , respectively) compare favorably, showing an absence of significant matrix effects. This was tested in the same way with injections of PCT to check whether the increase in $R_{\text {th }}$ was from the buildup of matter from the blood plasma on the surface of the electrode. As seen in Figure 3B, there was a significantly lower increase in the measured $R_{\mathrm{th}}$ for the addition of PCT in blood plasma. The increase in $R_{\mathrm{th}}$ for the addition of $100 \mathrm{pg} \mathrm{mL} \mathrm{m}^{-1} \mathrm{PCT}$ was measured to be $0.06{ }^{\circ} \mathrm{C} / \mathrm{W}$. This clearly shows that the sensing platform is specific for the detection of IL-6 in blood plasma, can deliver results in under 15 min after sample injection, and can be applicable as a traffic light-type sensor for increases in IL-6 concentration above clinically relevant physiological levels. A comparison of this methodology to others reported in the literature is presented in Table 1 . It is clearly evident from the inspection of Table 1 that the methodology presented here performs extremely well in comparison to other reported approaches. The vast majority of reported sensors for IL-6 utilize expensive or complex substrates, increasing the cost of materials or time of the sensor manufacture. In addition, our platform can report results in less than 15 min post sample injection, whereas most reported sensors take an hour or longer to report results, meaning our sensor would provide a diagnosis within the wellestablished "golden hour" of sepsis. ${ }^{2}$ This work utilizes facile coupling technology in conjunction with SPEs and a simple read out strategy, which would massively reduce the cost of production. Through optimization of the HTM setup into a portable device with direct injection onto the electrode, this system could potentially be able to report results in under 15 min after the injection of a very small sample volume (cell volume $=110 \mu \mathrm{L}) .^{20}$

When compared to other instances reported in the literature for the detection of IL-6, this work compares favorably with the limits of detection in the biologically relevant range. ${ }^{4 \mathrm{e}}$ In addition to this, the sensor platform is shown, herein, to work well in complex biological media, where many others cannot demonstrate this or require extensive sample pretreatment. This work shows that antibody functionalized SPEs can detect IL-6 at the clinically relevant ranges for a traffic light sensor that is giving on-the-spot results with optimization of the device suitable for deployment in intensive care unit (ICU) settings, which would greatly reduce patient mortality.

\section{CONCLUSIONS}

Screen-printed electrodes (SPEs) have been functionalized with antibodies specific for interleukin-6 (IL-6) through electrodeposition of a diazonium linking group and EDC/ NHS coupling. This modification was tracked and confirmed through electrochemical and Raman techniques. The modified SPEs were used for the detection of IL-6 in a PBS buffer solution and in blood plasma using the heat-transfer method (HTM). This is the first report in the literature for the use of antibodies in conjunction with the HTM or the use of the HTM to detect IL-6. The sensor platform was tested in PBS buffer, where increases in the measured thermal resistance were observed when IL- 6 was introduced to the system. Doseresponse curves were constructed, which showed excellent sensitivity for the detection of IL- 6 with a LOD of $3.4 \pm 0.2 \mathrm{pg}$ $\mathrm{mL}^{-1}$, which is within the physiologically relevant range. No significant interference was observed when introducing the 
sensor platform to a similarly sized protein in procalcitonin (PCT). These tests were repeated in blood plasma and again showed excellent sensitivity toward IL-6 and no significant interference from the presence of PCT or other moieties in the medium. This provided proof-of-application for the technology, indicating the possibility for its use in a healthcare setting as a traffic light sensor due to its clinically relevant detection levels, fast turnaround time, low cost of production, straightforward operation, and ability to tailor the sensor to other targets. Additionally, the ability to detect antigenantibody interactions exhibits the possibility to open up completely new fields of research for the HTM and thermal detection due to the vast array of uses for antibodies and the adaptability of the proposed sensing platform.

\section{ASSOCIATED CONTENT}

\section{SI Supporting Information}

The Supporting Information is available free of charge at https://pubs.acs.org/doi/10.1021/acs.analchem.1c00417.

Photographs of the experimental setup and interference testing (PDF)

\section{AUTHOR INFORMATION}

\section{Corresponding Authors}

Craig E. Banks - Faculty of Science and Engineering, Manchester Metropolitan University, Manchester M1 5GD, United Kingdom; 이이이.org/0000-0002-0756-9764; Phone: +441612471196; Email: c.banks@mmu.ac.uk

Nina C. Dempsey-Hibbert - Faculty of Science and Engineering, Manchester Metropolitan University, Manchester M1 5GD, United Kingdom; Phone: +441612471175; Email: n.dempsey-hibbert@mmu.ac.uk

\section{Authors}

Robert D. Crapnell - Faculty of Science and Engineering, Manchester Metropolitan University, Manchester M1 5GD, United Kingdom

Whitchuta Jesadabundit - Electrochemistry and Optical Spectroscopy Center of Excellence, Department of Chemistry, Faculty of Science, Chulalongkorn University, Patumwan, Bangkok 10330, Thailand

Alejandro García-Miranda Ferrari - Faculty of Science and Engineering, Manchester Metropolitan University, Manchester M1 5GD, United Kingdom

Marloes Peeters - Newcastle University, School of Engineering, Newcastle Upon Tyne NE1 7RU, United Kingdom; (1) orcid.org/0000-0002-0429-8073

Ascanio Tridente - Intensive Care Unit, Whiston Hospital, St Helens and Knowsley Teaching Hospitals NHS Trust, Prescot L35 5DR, United Kingdom

Orawon Chailapakul - Electrochemistry and Optical Spectroscopy Center of Excellence, Department of Chemistry, Faculty of Science, Chulalongkorn University, Patumwan, Bangkok 10330, Thailand

Complete contact information is available at: https://pubs.acs.org/10.1021/acs.analchem.1c00417

\section{Notes}

The authors declare no competing financial interest.

\section{ACKNOWLEDGMENTS}

A.G.-M.F. would like to acknowledge Innovate UK for funding his Knowledge Transfer Partnership (KTP Reference: 11606).

\section{REFERENCES}

(1) Fleischmann, C.; Scherag, A.; Adhikari, N. K.; Hartog, C. S.; Tsaganos, T.; Schlattmann, P.; Angus, D. C.; Reinhart, K. Am. J. Respir. Crit. Care Med. 2016, 193 (3), 259-272.

(2) Kumar, A.; Roberts, D.; Wood, K. E.; Light, B.; Parrillo, J. E.; Sharma, S.; Suppes, R.; Feinstein, D.; Zanotti, S.; Taiberg, L.; et al. Crit. Care Med. 2006, 34 (6), 1589-1596.

(3) Singer, M.; Deutschman, C. S.; Seymour, C. W.; Shankar-Hari, M.; Annane, D.; Bauer, M.; Bellomo, R.; Bernard, G. R.; Chiche, J.-D.; Coopersmith, C. M.; et al. Jama 2016, 315 (8), 801-810.

(4) (a) Burki, T. K. Lancet Respir. Med. 2018, 6 (11), 826. (b) Angurana, S. K.; Bansal, A.; Muralidharan, J.; Aggarwal, R.; Singhi, S. Journal of Intensive Care Medicine 2020, 0885066620912989. (c) Molano Franco, D. M.; Arevalo-Rodriguez, I.; i Figuls, M. R.; Oleas, N. G. M.; Nuvials, X.; Zamora, J. Cochrane Database of Systematic Reviews 2019, No. 4, CD011811. (d) Leal, Y. A.; ÁlvarezNemegyei, J.; Lavadores-May, A. I.; Girón-Carrillo, J. L.; CedilloRivera, R.; Velazquez, J. R. J. Matern.-Fetal Neonat. Med. 2019, 32 (17), 2830-2836. (e) Miguel-Bayarri, V.; Casanoves-Laparra, E.; Pallás-Beneyto, L.; Sancho-Chinesta, S.; Martín-Osorio, L.; TormoCalandín, C.; Bautista-Rentero, D. Medicina Intensiva (English Edition) 2012, 36 (8), 556-562. (f) Song, J.; Park, D. W.; Moon, S.; Cho, H.J.; Park, J. H.; Seok, H.; Choi, W. S. BMC Infect. Dis. 2019, 19 (1), 968.

(5) (a) Del Valle, D. M.; Kim-Schulze, S.; Huang, H.-H.; Beckmann, N. D.; Nirenberg, S.; Wang, B.; Lavin, Y.; Swartz, T. H.; Madduri, D.; Stock, A.; et al. Nat. Med. 2020, 26 (10), 1636-1643. (b) Herold, T.; Jurinovic, V.; Arnreich, C.; Lipworth, B. J.; Hellmuth, J. C.; von Bergwelt-Baildon, M.; Klein, M.; Weinberger, T. J. Allergy Clin. Immunol. 2020, 146, 128. (c) Tan, L.; Kang, X.; Ji, X.; Li, G.; Wang, Q.; Li, Y.; Wang, Q.; Miao, H. Med 2020, 1, 128.

(6) (a) Biran, N.; Ip, A.; Ahn, J.; Go, R. C.; Wang, S.; Mathura, S.; Sinclaire, B. A.; Bednarz, U.; Marafelias, M.; Hansen, E.; et al. Lancet Rheumatology 2020, 2 (10), e603-e612. (b) Stone, J. H.; Frigault, M. J.; Serling-Boyd, N. J.; Fernandes, A. D.; Harvey, L.; Foulkes, A. S.; Horick, N. K.; Healy, B. C.; Shah, R.; Bensaci, A. M. N. Engl. J. Med. 2020, 383, 2333.

(7) (a) Horby, P. W. Randomised Evaluation of COVID-19 Therapy (RECOVERY); Clinicaltrials.gov Identifier NCT04381936; University of Oxford, 2020; https://clinicaltrials.gov/ct2/show/NCT04381936. (b) Wang, C.; Takei, K.; Takahashi, T.; Javey, A. Chem. Soc. Rev. 2013, 42 (7), 2592-2609. (c) Bonten, M. Randomized, Embedded, Multifactorial Adaptive Platform Trial for Community-Acquired Pneumonia (REMAP-CAP); Clinicaltrials.gov Identifier NCT02735707; 2020; https://clinicaltrials.gov/ct2/show/NCT02735707.

(8) Usami, S.; Motoyama, S.; Koyota, S.; Wang, J.; Hayashi-Shibuya, K.; Maruyama, K.; Takahashi, N.; Saito, H.; Minamiya, Y.; Takasawa, S.; et al. Biochem. Biophys. Res. Commun. 2010, 392 (1), 4-8.

(9) (a) Anastasopoulou, M.; Malainou, A.; Salapatas, A.; Chronis, N.; Raptis, I.; Misiakos, K. Sens. Actuators, B 2018, 256, 304-309. (b) Kapoor, R.; Wang, C.-W. Biosens. Bioelectron. 2009, 24 (8), 26962701.

(10) (a) Li, T.; Yang, M. Sens. Actuators, B 2011, 158 (1), 361-365. (b) Malhotra, R.; Patel, V.; Vaqué, J. P.; Gutkind, J. S.; Rusling, J. F. Anal. Chem. 2010, 82 (8), 3118-3123. (c) Peng, J.; Feng, L. N.; Ren, Z. J.; Jiang, L. P.; Zhu, J. J. Small 2011, 7 (20), 2921-2928. (d) Yang, T.; Wang, S.; Jin, H.; Bao, W.; Huang, S.; Wang, J. Sens. Actuators, B 2013, 178, 310-315. (e) Russell, C.; Ward, A. C.; Vezza, V.; Hoskisson, P.; Alcorn, D.; Steenson, D. P.; Corrigan, D. K. Biosens. Bioelectron. 2019, 126, 806-814.

(11) (a) Deen, C.; Claassen, E.; Gerritse, K.; Zegers, N. D.; Boersma, W. J. J. Immunol. Methods 1990, 129 (1), 119-125. (b) Staros, J. V.; Wright, R. W.; Swingle, D. M. Anal. Biochem. 1986, 156 (1), 220-222. 
(12) Bouden, S.; Pinson, J.; Vautrin-Ul, C. Electrochem. Commun.

2017, 81, 120-123.

(13) Randriamahazaka, H.; Ghilane, J. Electroanalysis 2016, 28 (1), 13-26.

(14) (a) Li, M.; Li, Y.-T.; Li, D.-W.; Long, Y.-T. Anal. Chim. Acta

2012, 734, 31-44. (b) Metters, J. P.; Kadara, R. O.; Banks, C. E. Analyst 2011, 136 (6), 1067-1076.

(15) Yáñez-Sedeño, P.; Campuzano, S.; Pingarrón, J. M. Sensors 2018, 18 (2), 675.

(16) Van Grinsven, B.; Vanden Bon, N.; Strauven, H.; Grieten, L.; Murib, M.; Jiménez Monroy, K. L.; Janssens, S. D.; Haenen, K.; Schöning, M. J.; Vermeeren, V.; et al. ACS Nano 2012, 6 (3), 27122721.

(17) (a) Betlem, K.; Mahmood, I.; Seixas, R.; Sadiki, I.; Raimbault, R.; Foster, C.; Crapnell, R.; Tedesco, S.; Banks, C.; Gruber, J.; et al. Chem. Eng. J. 2019, 359, 505-517. (b) Jamieson, O.; Soares, T. C.; de Faria, B. A.; Hudson, A.; Mecozzi, F.; Rowley-Neale, S. J.; Banks, C. E.; Gruber, J.; Novakovic, K.; Peeters, M.; et al. Chemosensors 2020, 8 (1), 5 .

(18) (a) Canfarotta, F.; Czulak, J.; Betlem, K.; Sachdeva, A.; Eersels, K.; Van Grinsven, B.; Cleij, T.; Peeters, M. Nanoscale 2018, 10 (4), 2081-2089. (b) Crapnell, R. D.; Canfarotta, F.; Czulak, J.; Johnson, R.; Betlem, K.; Mecozzi, F.; Down, M. P.; Eersels, K.; van Grinsven, B.; Cleij, T. J.; et al. ACS sensors 2019, 4 (10), 2838.

(19) Betlem, K.; Kaur, A.; Hudson, A. D.; Crapnell, R. D.; Hurst, G.; Singla, P.; Zubko, M.; Tedesco, S.; Banks, C. E.; Whitehead, K.; et al. ACS Applied Bio Materials 2019, 2 (9), 3790-3798.

(20) Vandenryt, T.; Van Grinsven, B.; Eersels, K.; Cornelis, P.; Kholwadia, S.; Cleij, T. J.; Thoelen, R.; De Ceuninck, W.; Peeters, M.; Wagner, P. Sensors 2017, 17 (12), 2701.

(21) Foster, C. W.; Metters, J. P.; Kampouris, D. K.; Banks, C. E. Electroanalysis 2014, 26 (2), 262-274.

(22) Cumba, L. R.; Foster, C. W.; Brownson, D. A.; Smith, J. P.; Iniesta, J.; Thakur, B.; Do Carmo, D. R.; Banks, C. E. Analyst 2016, 141 (9), 2791-2799.

(23) (a) Eissa, S.; Zourob, M. Nanoscale 2012, 4 (23), 7593-7599. (b) Liu, G.; Liu, J.; Böcking, T.; Eggers, P. K.; Gooding, J. J. Chem. Phys. 2005, 319 (1-3), 136-146.

(24) Cinti, S.; Arduini, F.; Carbone, M.; Sansone, L.; Cacciotti, I.; Moscone, D.; Palleschi, G. Electroanalysis 2015, 27 (9), 2230-2238.

(25) Eissa, S.; Alshehri, N.; Rahman, A. M. A.; Dasouki, M.; AbuSalah, K. M.; Zourob, M. Biosens. Bioelectron. 2018, 101, 282-289.

(26) Radi, A.-E.; Munoz-Berbel, X.; Lates, V.; Marty, J.-L. Biosens. Bioelectron. 2009, 24 (7), 1888-1892.

(27) Fan, G.-C.; Ren, X.-L.; Zhu, C.; Zhang, J.-R.; Zhu, J.-J. Biosens. Bioelectron. 2014, 59, 45-53.

(28) Wang, G.; Huang, H.; Zhang, G.; Zhang, X.; Fang, B.; Wang, L. Langmuir 2011, 27 (3), 1224-1231.

(29) Tertis, M.; Leva, P. I.; Bogdan, D.; Suciu, M.; Graur, F.; Cristea, C. Biosens. Bioelectron. 2019, 137, 123-132.

(30) Liang, K.-Z.; Qi, J.-S.; Mu, W.-J.; Liu, Z.-X. Bioprocess Biosyst. Eng. 2009, 32 (3), 353-359.

(31) Turner, C. K.; Blieden, T. M.; Smith, T. J.; Feldon, S. E.; Foster, D. C.; Sime, P. J.; Phipps, R. P. J. Immunol. Methods 2004, 291 (1-2), 63-70.

(32) Chen, P.; Chung, M. T.; McHugh, W.; Nidetz, R.; Li, Y.; Fu, J.; Cornell, T. T.; Shanley, T. P.; Kurabayashi, K. ACS Nano 2015, 9 (4), $4173-4181$.

(33) Kumar, L. S.; Wang, X.; Hagen, J.; Naik, R.; Papautsky, I.; Heikenfeld, J. Anal. Methods 2016, 8 (17), 3440-3444. 